tion and the intrinsic value are the same. With regard to the English didactic method, we have been struck by a greater tendency towards a . systematic arrangement and simplification of methods; one receives the impression that the whole system of English education is based much more on visual representations than is the case with Italian methods, which are more verbal and abstract. This is particularly apparent and important in connection with primary and secondary instruction, which makes an excellent impression, both on account of the intuitive basis of the education and the distribution of subjects and time, as well as on account of the large part which is devoted to moral and physical training. In her conception of what elementary and secondary schools should be, both intrinsically and extrinsically (methods of teaching and scholastic buildings), England offers a notable example, which is worthy of study, especially by us Italians, for whom these problems are of the greatest importance, as the Government and the people are fully aware.

With regard to the universities, on the other hand, we were able to pursue our journey in company with English men of science, trusting to those spiritual affinities which have hitherto been of such great value in strengthening the friendship between our two peoples. Our visit to certain universities which were more particularly technical gave us great satisfaction for a different reason, since they showed us that they were well on the way towards that co-operation between the man of science and the industrialist which, with ourselves, has recently proved to be very effective. It is in virtue of a similar co-operation that the Italian universities have now, in some branches of education, an abundance of means which ensures their proper working; and it is hoped that not only the physico-chemical sciences, but also the biological sciences, to their full extent and application, will soon be enjoying the benefit of the assistance of the industrialists.

To the Italian delegation it seemed that the reciprocal knowledge of the languages of the two countries was the problem that had, in the first place, to be solved; the meetings at the Royal Society of Literature, the lectures delivered at various places that were visited, did much towards assisting the efforts in this direction, and it was certainly a great encouragement to us, coming from Italy at this grave moment to carry on a work of reconstruction, to find so much willingness expressed in the English manner, not in words alone, but in deeds as well, to spread the knowledge of our language, which is the chief and the most effective instrument of our union.

Piero Giacosa.

\section{APPLIED SCIENCE IN THE COTTON INDUSTRY.}

$\mathrm{O}^{\mathrm{P}}$

PINIONS may differ as to which is the most valuable or most important of the many aspects of this question which were set forth by Dr. Lawrence Balls in a paper entitled "Some Applications of Research to the Cotton Industry," read before the Roval Society of Arts on April Io, and published in the Journal of the society for May 3 (vol. 1xvi., p. 389 ). His contributions to the scientific and practical sides of the problem may appeal in varying degrees to different people, but no one could fail to be impressed by their compelling interest.

The necessity for scientific research is in danger of becoming a catchword which everyone repeats, though few have sufficient knowledge of what it means to have any real faith in it. Dr. Balls has shown that the scientific study of the cotton plant and its environ- ment is essential before the spinner can even describe what he wants in his raw material, in terms which can be translated by the plant-grower into efforts to produce the desired results. Even the question of length of staple has always been dependent on a ruleof-thumb method of determination which left the grower very much in the dark. On this point one might be tempted to award the major importance to Dr. Balls's invention of an ingenious machine which will not merely give the maximum and minimum length of individual hairs in a cotton sample, or even the average length, but will sort them out in graduated lengths and make it easy to measure the total quantity of each length, thus ascertaining accurately the degree of uniformity or otherwise of the staple, which is of prime importance to the spinner. The use of this machine should go a long way towards determining in a really definite way the value of any cotton sample, and may prove the main step towards a method which would enable the grower himself to estimate the suitability of a new cotton for a particular trade.

Equally valuable from the practical point of view was the hint which Dr. Balls's studies of flowering and bolling curves give of a scientific method of forecasting such crops as cotton. If it is not too good to be true, we may live to see the "arrivals" of the crop plotted out weeks in advance, and the probable total yield of the crop foreseer with an accuracy which would certainly be an improvement on the present rather haphazard and sometimes very deceptive methods.

The important results of the work out of which much of Dr. Balls's material arose, in its effects on the water control policy of the Egyptian Irrigation Department, is now a matter of history, but it is one which cannot be told too often either in scientific or official circles as an encouragement and stimulus to the one and a warning to the other.

\section{THE CO-ORDINATION OF ELECTRIC POWER SUPPLY.}

THE report of the Committee appointed by the Board of Trade to consider the question of electric power has now been issued (Cd. 9062, price $3 d$.). Several of the questions the Committee had to consider have already been dealt with by the Coal Conservation Sub-Committee, the report of which was described in NATURE of January 3 and February i4 last. The report begins by the statement. of several general conclusions on which it bases its recommendations. The first of these is that after the war the success of British industry will depend to a large extent on the adoption of the most efficient methods and machinery, so that manifacturing costs may be reduced to a minimum. In ihis connection the extension in the use of electric power supplied at the lowest possible price will be a most important factor. The present system of supply by separate authorities to small areas is economically unsound, and prevents the cheapening of the supply. Hence a comprehensive system for the generation of electricity and, where necessary, for reorganising its supply should be established as soon as possible. With these statements every engineer is in agreement. If it had been possible to work on a clean slate, the devising of a suitable scheme under a central authority would have been comparatively easy. Owing, however, to the existence of the present patchwork system and the many conflicting interests which will have to be adjusted, the problem is one of considerable complexity. The Committe advises that a new body to be called the Electricity Commissioners be set up, to whom the existing powers of the Board of Trade

NO. 2537 , VOL. IOI] 